\title{
Tenofovir Alafenamide versus Tenofovir Disoproxil Fumarate: Systematic Review and Meta-Analysis
}

\author{
Jacques Lukenze Tamuzi ${ }^{1 *}$, Jonathan Lukusa Tshimwanga ${ }^{2}$, Andre Nyandwe Hamama Bulabula ${ }^{3}$ and Ley

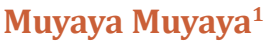 \\ 1Community Health Division, Stellenbosch University, South Africa
}

2Division of Family medicine, Stellenbosch University, South Africa

3Division of infectious diseases, Stellenbosch University, South Africa

Submission: February 27, 2018; Published: March 19, 2018

*Corresponding author: Jacques Lukenze Tamuzi, Community Health Division, Faculty of Medicine and Health Sciences, Stellenbosch University, Matieland, South Africa, Email: drjacques.tamuzi@gmail.com

Abstract

Background: Highly active antiretroviral therapy (HAART) has greatly reduced morbidity and mortality. Despite the impact of antiretroviral therapy (ART), mortality in successfully treated HIV infected patients remains higher than in the general uninfected population, more specifically in Sub-Saharan Africa. In fact, ART has demonstrated toxicity. tenofovir disoproxil (TDF) is widely known, even so, TDF is known as nephrotoxic. Recently, tenofovir alafenamide (TAF) was found. TAF is a new oral prodrug of tenofovir, less toxic than TDF. TAF has potential intracellular accumulation; lower extracellular exposures of tenofovir may be realized with the potential to reduce off-target toxicities. Additionally, TAF has shown its efficacy in HIV-Hepatitis B co-infection.

Objectives: To investigate whether TAF based regimens are less renal and borne toxic than TDF based regimens. To evaluate the efficacy of TAF versus TDF in HIV/hepatitis B co-infection.

Methods: We searched in studies in following databases: CENTRAL (Cochrane Central Register of Controlled Trials), Scopus, Web of science, LILACS, PubMed and CINAHL. We also searched conference abstract through HIV/AIDS website.

Main results: Among 916 studies found in different databases, 764 were screened after removing duplicate studies, 36 studies were included in qualitative studies. Among them, 16 studies were excluded with specific reasons. 18 RCTs were included in meta-analysis. Of the 12 RTCs assessing the OR of HIV-RNA<50RNAc/ml from 48 to 96 weeks, HIV-infected patients on TAF based regimens reduced HIV-RNA<50RNAc/ $\mathrm{ml}$ by $13 \%$ compared to TDF contained group ( $\mathrm{P}=0.02)$. For $10 \mathrm{RCTs}$ included in clearance creatinine rate comparing TAF to TFD based regimens, the glomerular filtration rate yielded a pooled MD estimate of $-3.94(-6.07$ to-1.81, $\mathrm{P}<0.000001)$. The OR of HBV- DNA after 48 weeks between TAF and TDF was reduced by 29\% (4 RCTs were included) with P=0.02. TDF individuals had a low MD of CD4 count (cells/ $\mu$ ) than TAF group (MD -18.99, 6 studies, $\mathrm{P}<00001$ ). The MD of percentage change hip bone mineral density was decreased in TFD compared to TAF -1.93 with $\mathrm{P}<0.00001$ and 11 RCTs were included as well as the MD of percentage change spine bone mineral density was decreased in TFD compared to TAF -1.77 (-1.97 to -1.58$)$ with $\mathrm{P}=0.001$. The odds of ALT above ULN was reduced by $25 \%$ in TAF group compared to TDF group ( $\mathrm{P}=0.04)$. Any adverse events and serious adverse events were not significant in both TAF and TDF groups. We graded the evidence as high in all outcomes except in bone Mineral Density and proteinuria where the evidence was respectively low and moderate.

Conclusion: Evidence suggests that use of TAF is more protective and effective than either TDF. Improving renal and hepatic related comorbidities in HIV-infected population, TAF may be beneficial in public health policy, specifically in high HIV epidemic regions.

Keywords: Tenofovir alafenamide; Tenofovir disoproxil fumarate; HIV; Hepatitis B

Abbreviations: HAART: Highly Active Antiretroviral Therapy; ART: Antiretroviral Therapy; TDF: Antiretroviral Therapytenofovir Disoproxil; TAF: Tenofovir Alafenamide; HAART: Highly Active Antiretroviral Therapy; PrEP: Pre-Exposure Prophylaxis; PI: Protease Inhibitors; GFR: Filtration Rate; Cr: Creatinine; GFR: Glomerular Filtration Rate; AKI: Acute Kidney Injury; CKDs: Chronic Kidney Diseases; GFR: Glomerular Filtration Rate

\section{Introduction}

HIV epidemic still carries a huge burden of morbidity and mortality in a wide part of the world, and according to the estimates of the Joint United Nations Programme on HIV/AIDS
[1], 36.7 million [30.8 million-42.9 million] people worldwide were living with HIV in 2016 [1]. In the same year [1.6 million-2.1 million] people were newly infected with HIV. Among them, 
830000 to 1.2 million died from acquired immunodeficiency syndrome (AIDS)-related causes [1]. 20.9 million People were accessing antiretroviral therapy in June 2017 [1]. The vast majority of people living with HIV are located in low- and middle- income countries, with an estimated 25.5 million living in sub-Saharan Africa. Among this group 19.4 million are living in East and Southern Africa which saw 44\% of new HIV infections globally in 2016 [2].

The region most affected by HIV epidemic is still sub-Saharan Africa where $4.9 \%$ of the adult population is HIV-infected, and the region itself accounts for $69 \%$ of people living with HIV globally [2]. The revolution of Highly active antiretroviral therapy (HAART) has greatly reduced morbidity and mortality, resulting then in high survival rates among infected patients [3-5]. Despite the impact of HAART, mortality and morbidity in successfully treated HIV infected patients remains higher than HIV uninfected population [2]. In fact, the effects of persistent inflammation in HIV infected population, antiretroviral toxicity on comorbidities that are related to HIV infection, including metabolic, cardiovascular and renal disease, contribute actively in high mortality and morbidity among HIV infected population [3-5]. Reviewing the literature and clinical data in Sub Saharan Africa, drug toxicity related mortality and mortality is occupying an important grade. Among those antiretroviral drugs, tenofovir disoproxil fumarate (TDF) is widely used. TDF-containing combinations antiretroviral therapy (ART) is currently considered as the first-line regimens for HIV treatment and prevention of mother-to-child transmission (РMTCT) Option $\mathrm{B} / \mathrm{B}+[6]$. Moreover, TDF is the approved drug for pre-exposure prophylaxis (PrEP) [6-9]. Knowing TDF nephrotoxicity, regular clearance creatinine monitoring is crucial in ART initiation and schedule monitoring. However, most Sub-Saharan African countries lack regular monitoring of clearance creatinine. Consequently, chronic kidney diseases prevalence are topping up in this region.

Recently, a systematic review has demonstrated that TDFcontaining regimens were associated with a significantly greater loss of kidney function. Furthermore, the review also found a significantly higher risk of acute renal injury associated with TDF use [9]. In spite of that, debate continues over whether more widespread use of TDF, particularly in "real world" clinical settings, might yet reveal a risk for nephrotoxicity significant enough to limit its use or to necessitate close clinical monitoring [7-9]. Previous studies have reported several risk factors for TDF-induced nephrotoxicity. Among them, include high basal serum creatinine ( $\mathrm{Cr}$ ) level, simultaneous use of nephrotoxic drugs, low body weight, old age, hypertension, diabetes mellitus and low CD4+ T cell count $[10,11]$. It is presumed that proximal tubule damage, decreased bone density, and reduced glomerular filtration rate (GFR) could also occur in association with TDF use $[12,13]$. Besides, the combinations with protease inhibitors (PI), specifically atazanavir can an additional decrease in GFR.
As a matter of fact, HIV-related renal diseases are one of the leading causes of chronic kidney diseases (CKDs) worldwide [14]. CKD is defined by a sustained change in urinary sediment, such as the presence of proteinuria, or by a reduced glomerular filtration rate (GFR) [15]. Nephrotoxicity can appear either during long or short-term use of TDF. TDF-induced nephrotoxicity is reported in about $15 \%$ of patients treated with TDF for 2-9 years $[16,17]$. TDF can also cause acute kidney injury (AKI), proximal tubular dysfunction, or both in combination [18]. In addition, interstitial nephritis, renal tubular damage, and nephrolithiasis have been detected as renal complications of HIV infection $[16,17]$. Proteinuria is often the earliest manifestation of CKD and is more common in HIV-infected individuals than in similarly aged HIV-negative controls [18]. Recently, Tenofovir alafenamide (TAF), a new oral prodrug of tenofovir, a nucleotide analogue that inhibits HIV-1 transcription was found [19]. This prodrug is already used in America, Europe and Oceania. Experimental studies have illustrated that TAF is more stable in plasma than TDF (Figure 1) and then is specifically converted into tenofovir within cells by the cellular enzyme cathepsin A, which is highly expressed in lymphoid tissues (Figure 1) [20]. Tenofovir is then further metabolized intracellularly to the active metabolite, tenofovir diphosphate, a competitive inhibitor of HIV-1 reverse transcriptase that terminates the elongation of the nascent viral cDNA chain [21]. Given the intracellular mechanism of activation of TAF and potential for intracellular accumulation, by the way, lower extracellular exposures may be realized with the potential to reduce renal toxicities [21]. Specifically, lower drug exposures to kidney cells may provide for fewer renal complications as observed in a minority of patients treated with TDF and the ability to dose TAF in patients with renal impairment without dose adjustment [9,16-19].

That is why, TAF was identified as an alternate TFV prodrug to TDF that more efficiently loads HIV-target cells [21]. A recent study demonstrated that TAF is 1000 - and 10 -fold more active against HIV in vitro than TFV or TDF, respectively [21]. The majority of intact TAF transits directly into its lymphoid cell target, where it is then converted intracellularly to tenofovir diphosphate [22-24]. Following dosing with TAF, the resulting systemic exposure to TFV is $91 \%$ lower than is the case for an equipotent dose of TDF $[25,26]$. This in-target cell conversion of prodrug minimizes systemic exposure to TFV [27]. TAF is not a substrate for renal organic anion transporters and this, along with the lower plasma levels of TFV, has been demonstrated to confer a better renal safety profile than that associated with TDF [27].

TAF was recently approved for the treatment of HIV-1 infection in the US and EU as part of the single-tablet regimen [19]. The evidence to date suggests that this TAF-containing regimen offers high virological success rates that are similar to those of TDFbased regimens, with a more favorable safety and tolerability profile, characterized by less impact on multiple measures of renal function and less impact on bone mineral density (BMD) in 
both treatment-naive and treatment experienced patients [28]. Indeed, data from studies in virologically suppressed patients with either normal renal function or mild to moderate renal impairment (eGFR 30-69mL/min), suggest that TAF may offer TFV-equivalent potency together with an improved renal and bone safety profile.

Besides, this review emphasize the role of TAF in HIV/ hepatitis B co-infection. In fact, chronic hepatitis B virus (HBV) infection is one of the leading causes of cirrhosis, liver decompensating, and hepatocellular carcinoma (HCC). An estimated 257 million people are positive for hepatitis B surface antigen (HBsAg) globally. HIV-Hepatitis B co-infection is common and TDF based regimens are the most used to control chronic hepatitis B. Both TAF and TDF are phosphonoamidate prodrugs of tenofovir (TFV) that share the same intracellular active metabolite, TFV diphosphate (TFV-DP), which is effective against both HBV and HIV-1 infection [29-31]. However, TAF has greater plasma stability as shown above, allowing then more efficient TAF uptake by hepatocytes at lower plasma concentrations than TDF (Figure 1), thus the circulating concentration of TFV is $90 \%$ lower after administration of a $25 \mathrm{mg}$ dose of TAF than after a $300 \mathrm{mg}$ dose of TDF [32-34]. Studies have shown that the efficacy of TAF was not inferior to that of TDF for both HBeAg-positive and -negative patients in regards to virologic outcomes $[35,36]$. However, the rate of (alanine transaminase) ALT normalization by the more stringent American Association Study of Liver Diseases (AASLD) criteria was significantly higher for TAF than for TDF. This systematic review is crucial in its genre because the results could play a role of turnover in changing the use of TDF to TAF, decreasing then nephrotoxicity due to TDF based regimens in both HIV-infected and not infected with HIV in the case post exposure prophylaxis [39]. In addition, other fields are investigated among which HIV viral load, CD4 count and bone mineral density. Moreover, this study is also focused on comparing TAF to TDF to control HIV-hepatitis B co-infection.

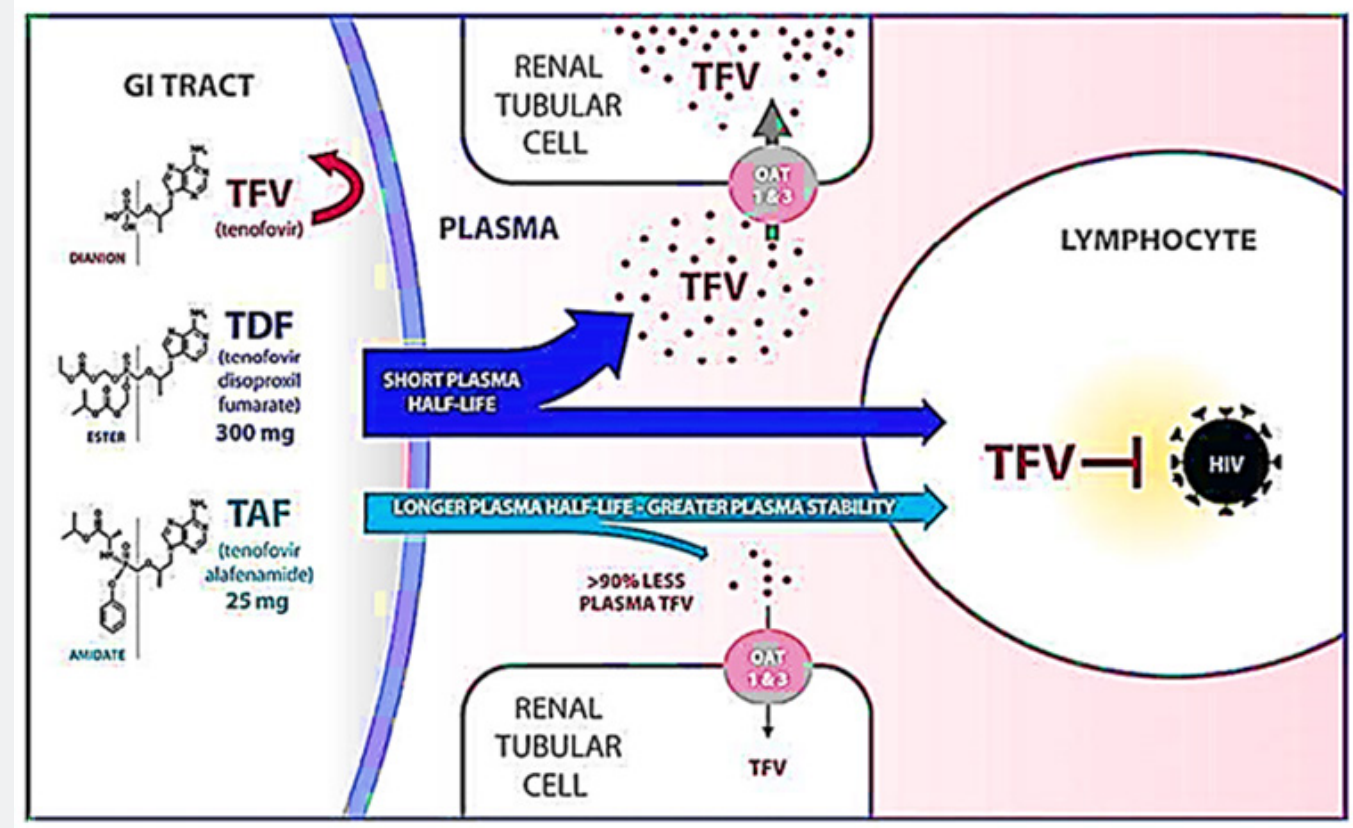

Figure 1: TAF vs TDF: renal tubular cells accumulation and plasma stability.

\section{Objectives}

a. To evaluate the efficacy of TAF based regimens are compared to TDF based regimens.

b. To investigate whether TAF based regimens are less renal and borne toxic than TDF based regimens.

c. To compare whether TAF contained regimens is more effective in HIV/HIB co-infection compared to TDF.

\section{Methods}

This systematic review was reported in accordance with the Preferred Reporting Items for Systematic Review and Meta-
Analyses statement. A protocol was registered with international prospective register of systematic reviews (PROSPERO) (identification number: CRD42016032717). This protocol could be found online at http://www.crd.york.ac.uk/PROSPERO/ display_record.asp?ID=CRD42016032717.

\section{Included studies definitions}

For all included studies, the intervention was TAFcontained regimens and the control group was TDF contained regimens. We included only parallel randomized control trials in which the participants were HIV-infected adult patients. The outcomes were included viral load, serum clearance creatinine, proteinuria, HBV DNA and HBsAg as primary outcomes and 
secondary outcomes were bone mineral density, CD4 count, hepatic transminases and adverse events.

\section{Search strategy, selection criteria, data extraction}

CENTRAL (Cochrane Central Register of Controlled Trials), Scopus, Web of science, LILACS, PubMed, CINAHL and MEDLINE were systematically searched without language, publication or date restrictions using key words and MeSH designed MeSH descriptor HIV Infections explode all trees AND MeSH descriptor HIV explode all trees AND (hiv OR hiv-1* OR hiv-2* OR hiv1 OR hiv2 OR hiv infect* OR human imminodeficiency virus OR human immune-deficiency virus OR human immuno-deficiency virus OR human immun* deficiency virus OR acquired immunodeficiency syndrome) AND (tenofovir OR TNF OR TDF OR PMPA OR Tenofovir Disoproxil OR Tenofovir Disoproxil Fumarate OR (Disoproxil Fumarate, Tenofovir) OR Fumarate, Tenofovir Disoproxil OR Viread) AND (Tenofovir alafenamide OR tenofovir prodrug OR TAF OR Vimlidy) AND (Randomized controlled trial) OR (controlled clinical trial) OR (randomized controlled trials) OR (random allocation) OR (double-blind method) OR (single-blind method) OR (clinical trial) OR (trial) OR (clinical trials) OR (clinical trial) OR (singl* OR doubl*) OR (trebl* OR tripl*) AND (mask* OR blind*) OR (placebos) OR (placebo*) OR (random*) on June December 2017. A combination of MeSH and ENTREE headings were used with free-text terms to enhance the sensitivity of the search. We further search conference abstract archives on the web sites of the Conference on Retroviruses and Opportunistic Infections (CROI), the International AIDS Conference (IAC), and the International AIDS Society Conference on HIV Pathogenesis, Treatment and Prevention (IAS). All references in review articles found by our database search were included using Revman Software [40]. Three investigators (JLT, LMM and JLT) independently screened and assessed titles and abstracts for inclusion. Full texts were independently assessed for inclusion and study type by JLT and JLT with disagreements resolved by discussion. JLT, LMM and JLT extracted the data. The methodology used for collecting and analyzing data was based on the guidance of the Cochrane Handbook of Systematic Reviews of Interventions [41]. JLT and JLT worked independently reviewed the abstracts of all studies identified through database searches or other resources. Full texts of the articles were obtained for closer examination.

Data extraction sheets were recorded: first author, study design publication year, study years, study settings country, trial identification number, published or unpublished, Follow up: duration and completeness of follow up, Study power, Details of participants(Baseline: age range; gender; CD4 count, viral load, HIV stage, Details of treatment), outcomes(primary and secondary) and Risk of bias assessment. We solved missing data in different ways. We obtained the standard deviations (SDs) from standard errors, confidence intervals, t-value and p-values. However, some studies did not report the SDs. Then, we contacted study authors to obtain missing data. Three RCTs included missing data. We deal with these issues by using amputation [41]. Quality of individual studies was assessed using the Cochrane tool for randomized control trials with six domains [41]: Sequence generation: how the allocation sequence was generated and described whether it was adequate

a. Allocation concealment: how the allocation sequence was concealed and clarified whether it was adequate.

b. Blinding of participants, personnel, and outcome assessors.

c. The description of the completeness of outcome data for each outcome.

d. Selective outcome reporting was assessed and funnel plots were generated in case that the outcome included ten or more studies.

e. Other potential sources of bias. Two reviewers (JLT and LMM) assessed independently the risk of bias in included study.

Each domain, the quality was graded and reported as high, low, or moderate risk of bias. In addition, we assessed reporting bias by using the funnel plots respectively for HIV-RNA<50RNAc/ $\mathrm{ml}$, Glomerular filtration rate $(\mathrm{ml} / \mathrm{min})$, Mean percentage change Hip Bone Mineral Density (\%) and Mean percentage change Spine Bone Mineral Density (\%).

\section{Data Synthesis}

We found that data from studies are as similar as possible and then we combined in Cochrane's Review Manager Software [40] for meta-analysis for the different outcomes. The study populations, interventions, outcomes and study designs were sufficiently similar across the studies' critical appraisal. This is why we pooled the data across studies and estimate summary effect sizes using both fixed- and random effects models. When assessing outcome, for continuous outcomes (serum clearance creatinine, CD4, Mean percentage change Bone Mineral Density), we used mean differences and its $95 \% \mathrm{CI}$, and for dichotomous outcomes (HIV-RNA<50, HBV DNA, Virological Failure, Proteinuria, ALT above ULN, and adverse events), we compared proportions in TAF and TDF group using the odd ratio and it 95\% CI.

The I2 test of heterogeneity was performed to ensure that the differences between the results of each RCT could not be expected by chance. Where we find substantial heterogeneity (I2 greater than 50\%), we investigated main reasons for the heterogeneity. By the way, subgroup analysis was undertaken. Subgroups analysis was performed by HIV-RNA baseline and different TAF and TDF regimens (Duranavir/cobicistat/TAF versus Duranavir/cobicistat/TDF; Elvitegravir/cobicistat/TAF versus Elvitegravir/cobicistat/TDF and Efavirenz/Elvitegravir/ 
TAF versus Efavirenz/Elvitegravir/TDF). HIV-RNA<50RNAc/ $\mathrm{ml}$, Glomerular filtration rate $(\mathrm{ml} / \mathrm{min})$ and Mean percentage change Bone Mineral Density (\%) included more than 10 RCTs in meta-analysis, then we produced funnel plots to assess evidence of publication bias. We performed Egger test in case that the funnel plots were asymmetric. All statistical analyses were undertaken using Revman $[40,41]$ statistical software. However, we handled missing data and publication bias by using STATA version 14. GRADE evidence profiles and summary of findings tables was assessed using Grade profile software. We graded different results as high, moderate, low or very low evidence based on studies designs included in meta-analysis, risk of bias, inconsistency, and indirectness and imprecision.

\section{Results}

Of the 916 studies found in different database, 764 were screened after removing duplicate studies, 36 studies were included in qualitative studies (Figure 2). Among them, 16 studies $[25,29,30,42-54]$ were excluded with specific reasons. [38] is an ongoing study. 18 studies [26,31,55-70] were included in meta-analysis (Figure 2). Characteristics of included and excluded studies are described in annexed tables (Figure 2).

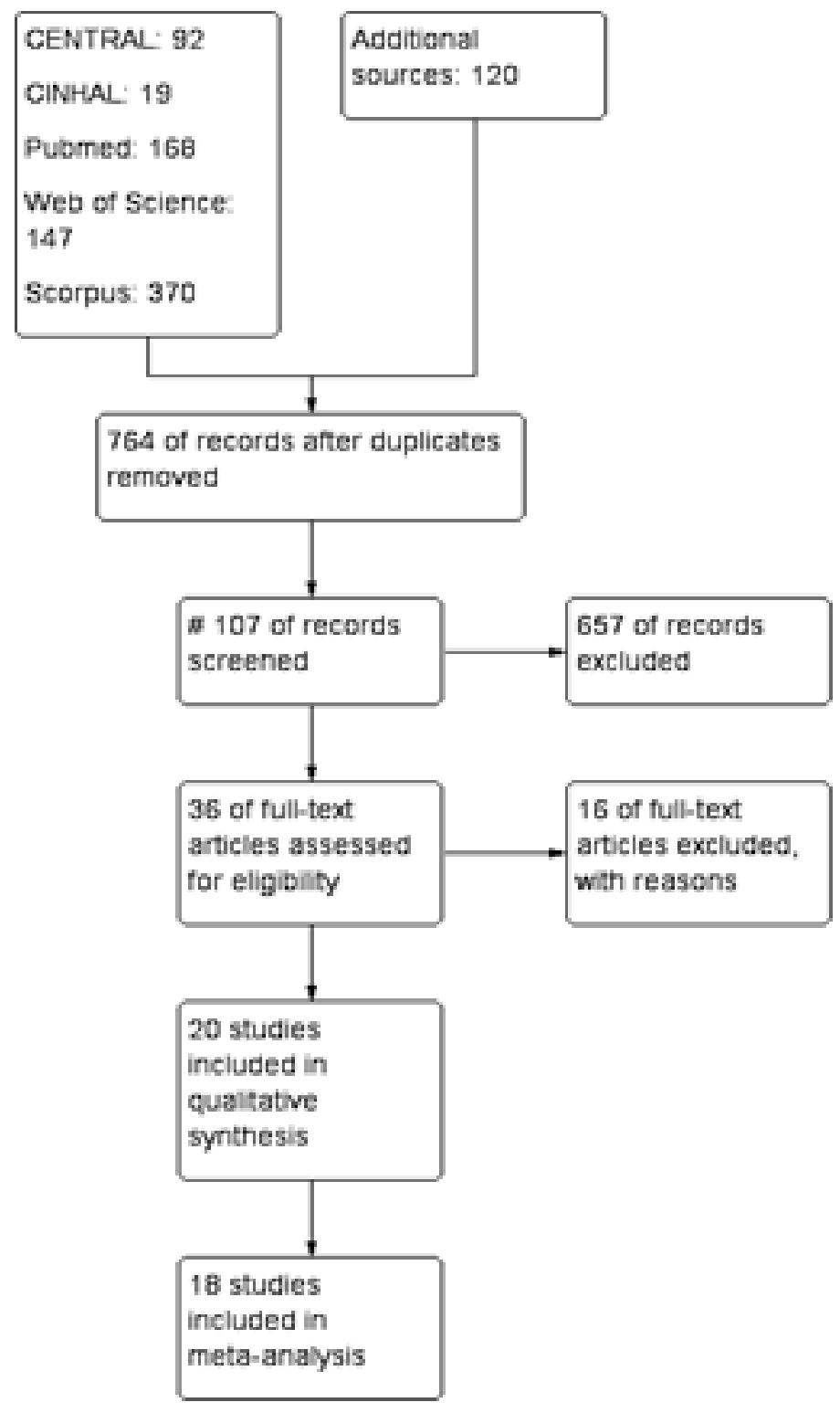

Figure 2: Flow diagram. 


\section{Meta-analysis}

HIV-RNA<50, Virological Failure, HBV DNA, HBeg, Glomerular filtration rate $(\mathrm{ml} / \mathrm{min})$, Proteinuria, CD4 cells/ ml, Mean percentage change Hip Bone Mineral Density (\%), Mean percentage change Spine Bone Mineral Density (\%), any adverse events, Serious adverse events and ALT above ULN were assessed through meta-analysis.

HIV-RNA<50RNAc/ml (48 to 144 weeks): Of the 12 RTCs assessing HIV-RNA<50RNAc/ml from 48 to 96 weeks, the fixedeffects meta-analysis of HIV-infected patients on TDF based regimens compared TAF contained regimens gave an $\mathrm{OR}$ of 0.87
( $95 \%$ CI 0.7 to $0.98, \mathrm{P}=0.02$ ) with $\mathrm{I} 2=50 \%$ (Figure 3 ). The overall evidence was graded as high.

Virological failure (48 to 144 weeks): Among the five studies that included in meta-analysis of virological failure, TAF group was less likely to treatment failure compared to TDF (OR 0.92, $95 \%$ CI 0.65 to 1.29 ).

Creatinine Clearance rate(ml/min) (48 to 144 weeks): For 10 RCTs included in creatinine clearance rate comparing TAF to TFD based regimens, the random-effects meta-analysis of glomerular filtration rate yielded a pooled MD estimate of $-3.94(95 \% \mathrm{CI}$ -6.07 to-1.81, $\mathrm{P}<0.000001$ ) with $\mathrm{I} 2=100 \%$ (Figure 4 ).

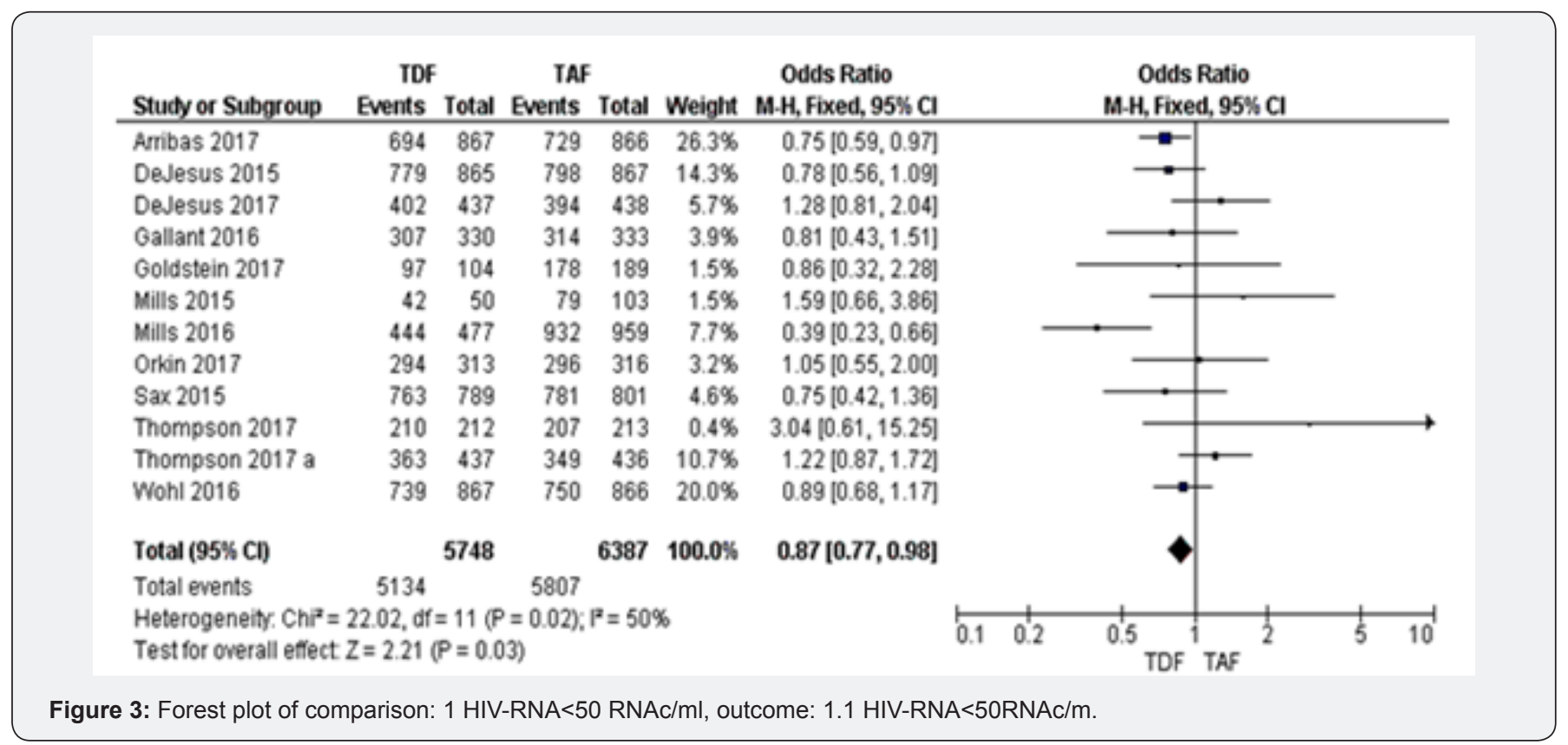

\begin{tabular}{|c|c|c|c|c|c|c|c|c|c|}
\hline Study or Subgroup & $\begin{array}{r}\text { TDF } \\
\text { Events }\end{array}$ & Total & $\begin{array}{r}\text { TAF } \\
\text { Events }\end{array}$ & Total & Weight & $\begin{array}{c}\text { Odds Ratio } \\
\text { M.H, Fixed, } 95 \% \mathrm{CI}\end{array}$ & & $\begin{array}{c}\text { Odds Ratio } \\
\text { M.H, Fixed, 95\% Cl }\end{array}$ & \\
\hline Amibas 2017 & 12 & 867 & 12 & 866 & $17.3 \%$ & $1.00[0.45,2.24]$ & & & \\
\hline Devesus 2015 & 5 & 865 & 7 & 867 & $10.1 \%$ & $0.71[0.23,2.26]$ & & & \\
\hline Gallant 2016 & 5 & 330 & 1 & 333 & $1.4 \%$ & $5.11[0.59,43.96]$ & & & \\
\hline Mills 2016 & 6 & 477 & 10 & 959 & $9.6 \%$ & $1.21[0.44,3.35]$ & & & \\
\hline Wohl 2016 & 35 & 867 & 44 & 867 & $61.6 \%$ & $0.79[0.50,1.24]$ & & ? & \\
\hline Total (95\% Cl) & & 3406 & & 3892 & $100.0 \%$ & $0.92[0.65,1.29]$ & & & \\
\hline Total events & 63 & & 74 & & & & & & \\
\hline $\begin{array}{l}\text { Heterogeneity. } \mathrm{Chi}^{2}= \\
\text { Test for overall effect }\end{array}$ & $\begin{array}{l}3.39, \mathrm{df}= \\
Z=0.49(\end{array}$ & $\begin{array}{l}4(P= \\
P=0.6\end{array}$ & $\begin{array}{l}0.49) ; \\
63)\end{array}$ & $=0 \%$ & & & 0.10 .2 & $0.5{ }^{1}{ }^{2}{ }^{2}$ & 510 \\
\hline
\end{tabular}

Therefore, the results were not statistically significant with $\mathrm{P}=0.63$. The results were homogenous with $\mathrm{I} 2=0 \%$ (Figure 4 ). The evidence was judged as high. We graded the evidence as low. Statistical heterogeneity was high between included studies; this is was subgroup analysis was undertaken for justification.

Proteinuria (48 to 144 weeks): Compared to individuals on TAF contained regimens, proteinuria was higher in TDF group OR 1.11 (95\% CI 0.81 to $1.54, \mathrm{P}=0.03$ ), with high quality of 
evidence. The results were heterogeneous $(I 2=64 \%)$, but the five individual point estimates were independently significant (Figure 5).

HBV DNA after 96 weeks: Four RCTs were included in metaanalysis assessing HBV DNA between TAF and TDF. The results were only significant in one study which weight was high, and then this study influenced the overall results OR 1.29 (95\%CI 1.05 to $1.59, \mathrm{P}=0.02$ ). There were three smallest studies that reported a non-significant increase of HBV DNA odds. Varying the estimation method from random effect to fixed model did not change the statistical significance but it reduced the point estimate by $7 \%$. However, HBV DNA was decreased by $29 \%$ in TAF group compared to TDF group. The results were moderately heterogeneous ( $12=51 \%$ ), mostly due to the three studies that showed a point estimate included the null value. The overall evidence was judged as high (Figure $6 \& 7$ ).

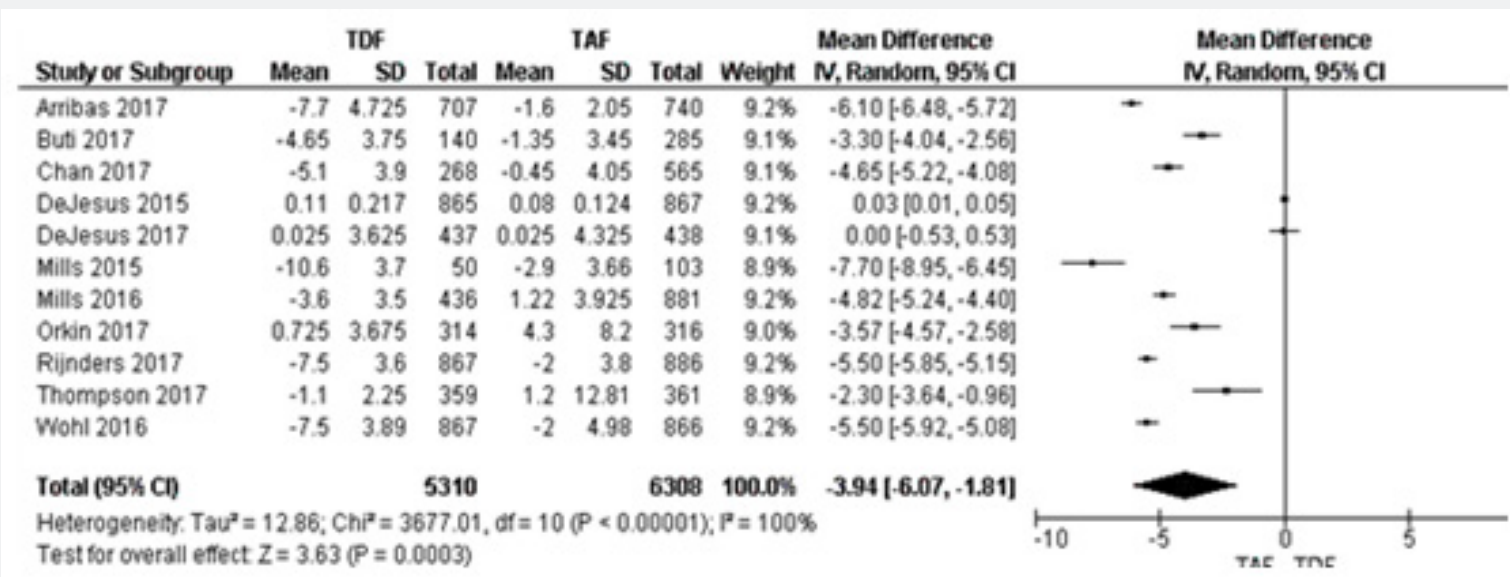

Figure 5: Meta-analysis of creatinine clearance $(\mathrm{ml} / \mathrm{min})$ in HIV-infected individuals: TAF vs. TDF.

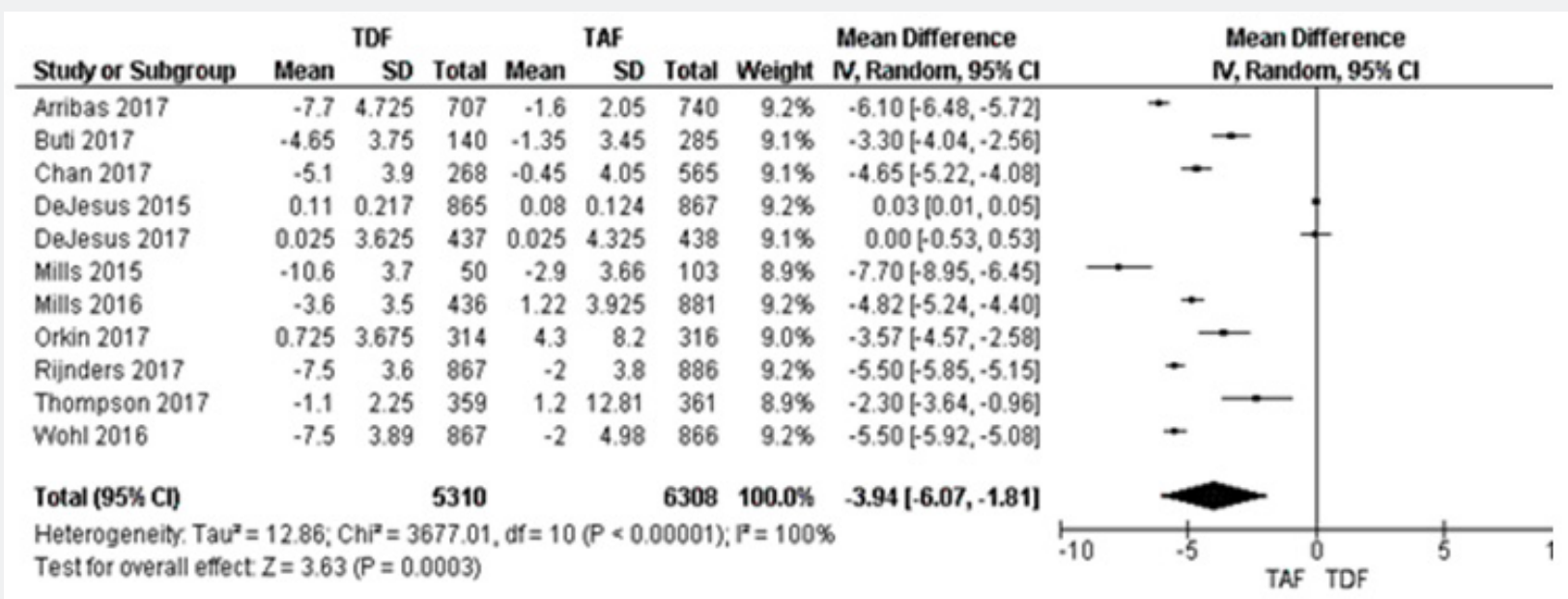

Figure 6: Odds of proteinuria in HIV+ individuals on TAF vs. TDF.

CD4 count (cells/ $\mu$ l) (48 to 144 weeks): TDF individuals had a low MD of CD4 count than TAF group (MD -18.99, 95\% CI -19.61,18.37, $\mathrm{P}<00001)$. Among six included studies, the results were consistent four studies, with higher point estimates (Arribas 2017; Dejesus 2015; Mills 2015; Sax 2015). These results were graded as high evidence. The results were homogenous (I2=0\%) and insensitive to the effect estimation method. The mean difference of percentage change hip BMD was decreased in TFD compared to TAF $-1.93(-2.21$ to -1.65$)$ with $\mathrm{P}<0.00001$. These results have shown low evidence that hip BMD is more likely to decrease in TDF group compared to TAF group. The results were highly heterogeneous (I2=89\%) (Figure 8 \& 9).
Mean percentage change Spine BMD (\%) (48 to 144 weeks): Eleven RCTs were included in this meta-analysis. All of them were statistically significant with random effect model. Transforming from fixed to random effect, the overall results decreased to $1.6 \%$. The mean difference of percentage change spine BMD was decreased in TFD compared to TAF -1.77 (-1.97 to -1.58$)$ with $\mathrm{P}=0.001$ (Figure 10).

ALT above ULN (96 weeks): ALT above ULN reached the lowest odds in TAF group compared to TDF group (OR 0.75, 0.57 to 0.98), the two studies included in this meta-analysis were not statistically. These results have shown moderate evidence that 
spine BMD is more likely to decrease in TDF group compared to TAF group. The results were moderately heterogeneous (I2 = $68 \%)$. Significant; however, the overall results were statistically significant with $\mathrm{P}=0.04$. The meta-analysis was graded as high evidence. The test of heterogeneity was I2=0 (Figure 11).

\begin{tabular}{|c|c|c|c|c|c|c|c|c|c|c|}
\hline Study or Subgroup & $\begin{array}{l}\text { TDF } \\
\text { Events }\end{array}$ & Total & $\begin{array}{l}\text { TAF } \\
\text { Events }\end{array}$ & Total & Weight & $\begin{array}{c}\text { Odds Ratio } \\
\text { M-H, Fixed, } 95 \% \mathrm{Cl}\end{array}$ & & $\begin{array}{r}\text { Odds F } \\
\text { M-H, Fixed }\end{array}$ & $\begin{array}{l}\text { Ratio } \\
\text { ed, } 95 \% \mathrm{Cl}\end{array}$ & \\
\hline Aganwal 2015 & 5 & 10 & 7 & 10 & $2.2 \%$ & $0.43[0.07,2.68]$ & $\longleftarrow$ & & & \\
\hline Buti 2017 & 24 & 140 & 60 & 285 & $20.9 \%$ & $0.78[0.46,1.31]$ & & 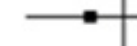 & 一 & \\
\hline Gane 2017 & 247 & 411 & 426 & 835 & $71.4 \%$ & $1.45[1.14,1.84]$ & & & - & \\
\hline Ricco 2017 & 133 & 140 & 263 & 285 & $5.5 \%$ & $1.59[0.66,3.82]$ & & & & \\
\hline Total $(95 \% \mathrm{Cl})$ & & 701 & & 1415 & $100.0 \%$ & $1.29[1.05,1.59]$ & & & & \\
\hline Total events & 409 & & 756 & & & & & & & \\
\hline $\begin{array}{l}\text { Heterogeneity. } \mathrm{Chi}^{2}= \\
\text { Test for overall effect }\end{array}$ & $\begin{array}{l}6.10, d f= \\
Z=2.41\end{array}$ & $\begin{array}{l}3(P=1 \\
P=0.0\end{array}$ & $\begin{array}{l}0.11) ; 1^{2}= \\
2 \text { ) }\end{array}$ & $=51 \%$ & & & $\begin{array}{ll} \\
0.1 & 0.2\end{array}$ & 0.5 TAF $^{1}$ & $i_{\text {TOF }}^{2}$ & $\begin{array}{ll}1 \\
5 & 10\end{array}$ \\
\hline
\end{tabular}

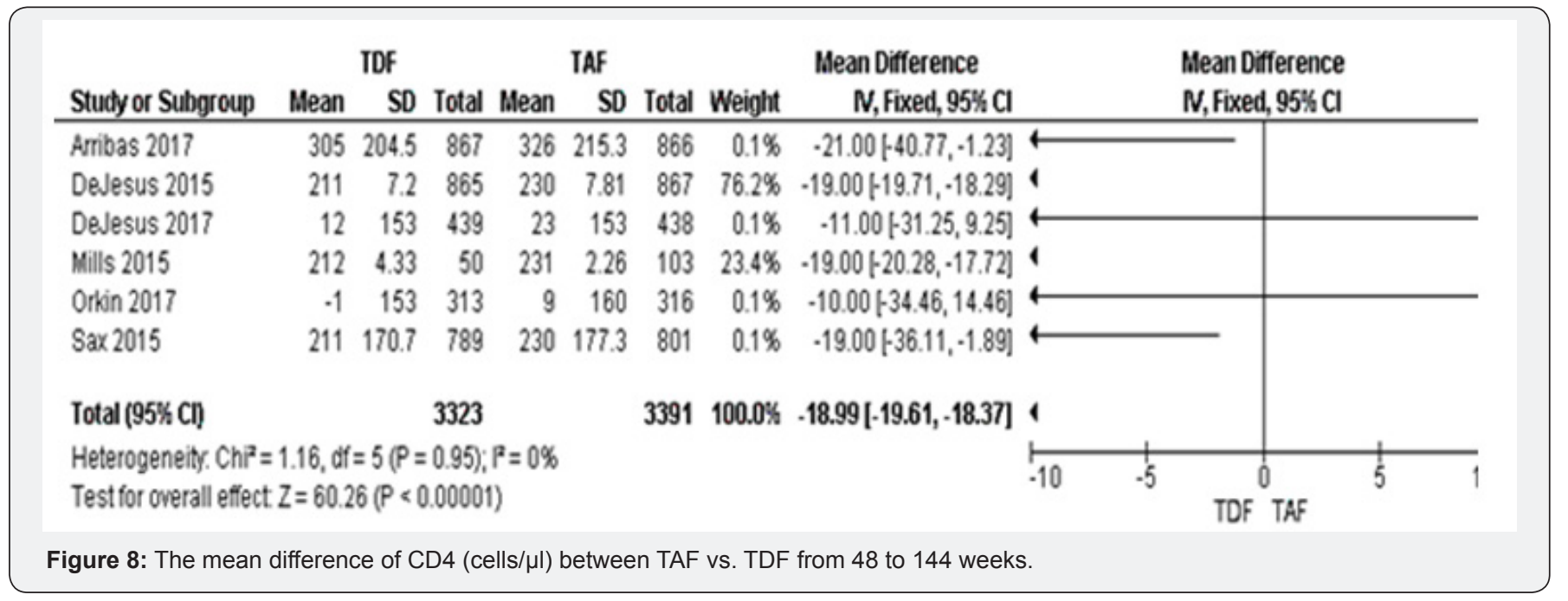

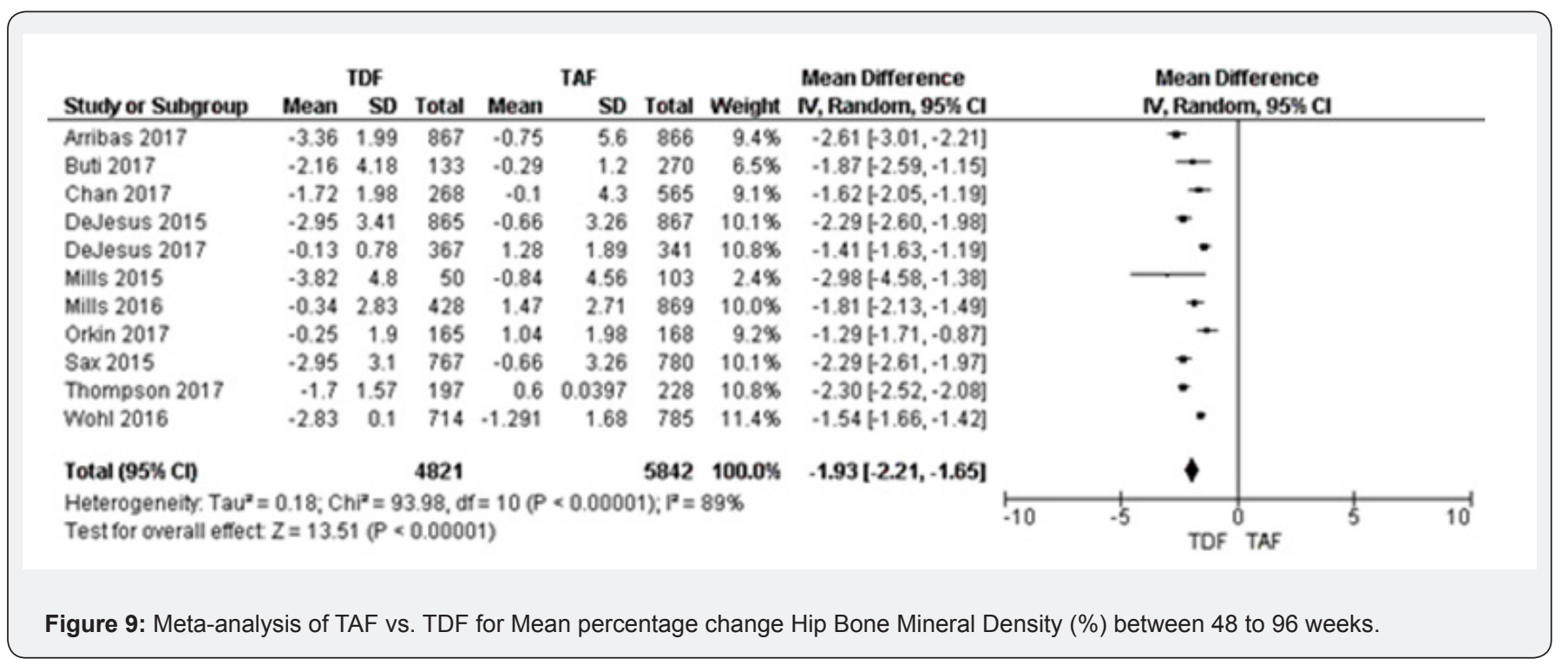




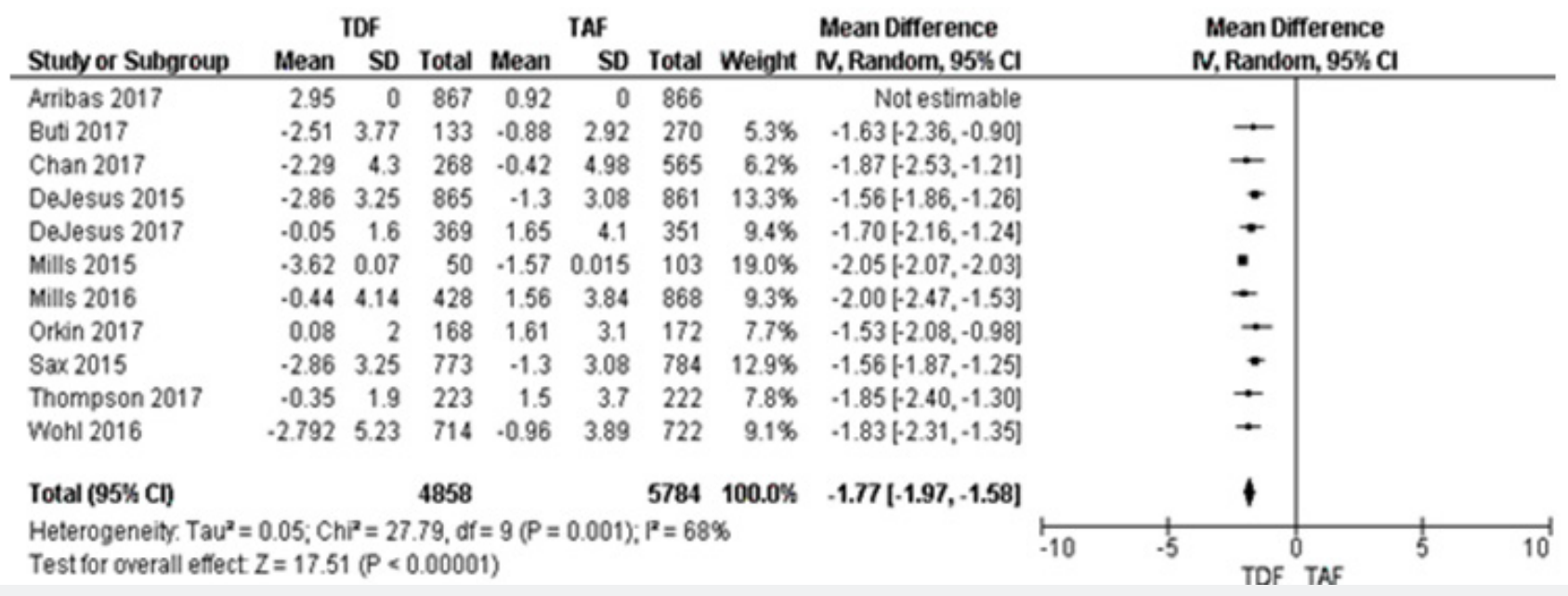

Figure 10: Meta-analysis of TAF vs. TDF for Mean percentage change Spine Bone Mineral Density (\%) between 48 to 96 weeks.

\begin{tabular}{|c|c|c|c|c|c|c|c|c|c|c|c|}
\hline Study or Subgroup & $\begin{array}{l}\text { IDF } \\
\text { Events }\end{array}$ & Total & $\begin{array}{c}\text { TAF } \\
\text { Events }\end{array}$ & Total & Weight & $\begin{array}{c}\text { Odds Ratio } \\
\text { M-H, Fixed, 95\% CI }\end{array}$ & & $\begin{array}{r}\text { Odds F } \\
\text { M.H, Fixed }\end{array}$ & $\begin{array}{l}\text { Ratio } \\
\text { d, } 95 \% \mathrm{Cl}\end{array}$ & & \\
\hline Buti 2017 & 91 & 121 & 196 & 236 & $28.0 \%$ & $0.62[0.36,1.06]$ & & & & & \\
\hline Chan 2017 & 179 & 268 & 384 & 537 & $72.0 \%$ & $0.80[0.58,1.10]$ & & & & & \\
\hline Total (95\% CI) & & 389 & & 773 & $100.0 \%$ & $0.75[0.57,0.98]$ & & & & & \\
\hline Total events & 270 & & 580 & & & & & & & & \\
\hline $\begin{array}{l}\text { Heterogeneity: } \mathrm{Chi}^{2}= \\
\text { Test for overall effect }\end{array}$ & $\begin{array}{l}0.66, \mathrm{df}= \\
\mathrm{Z}=2.07\end{array}$ & $\begin{array}{l}1(P= \\
P=0.0\end{array}$ & $\begin{array}{l}0.42): P^{2}= \\
\text { 4) }\end{array}$ & $=0 \%$ & & & $\begin{array}{ll}0.1 & 0.2\end{array}$ & $0.5{ }^{1}{ }^{1}{ }^{1}$ & TDF $^{2}$ & 5 & $\overline{1}$ \\
\hline
\end{tabular}

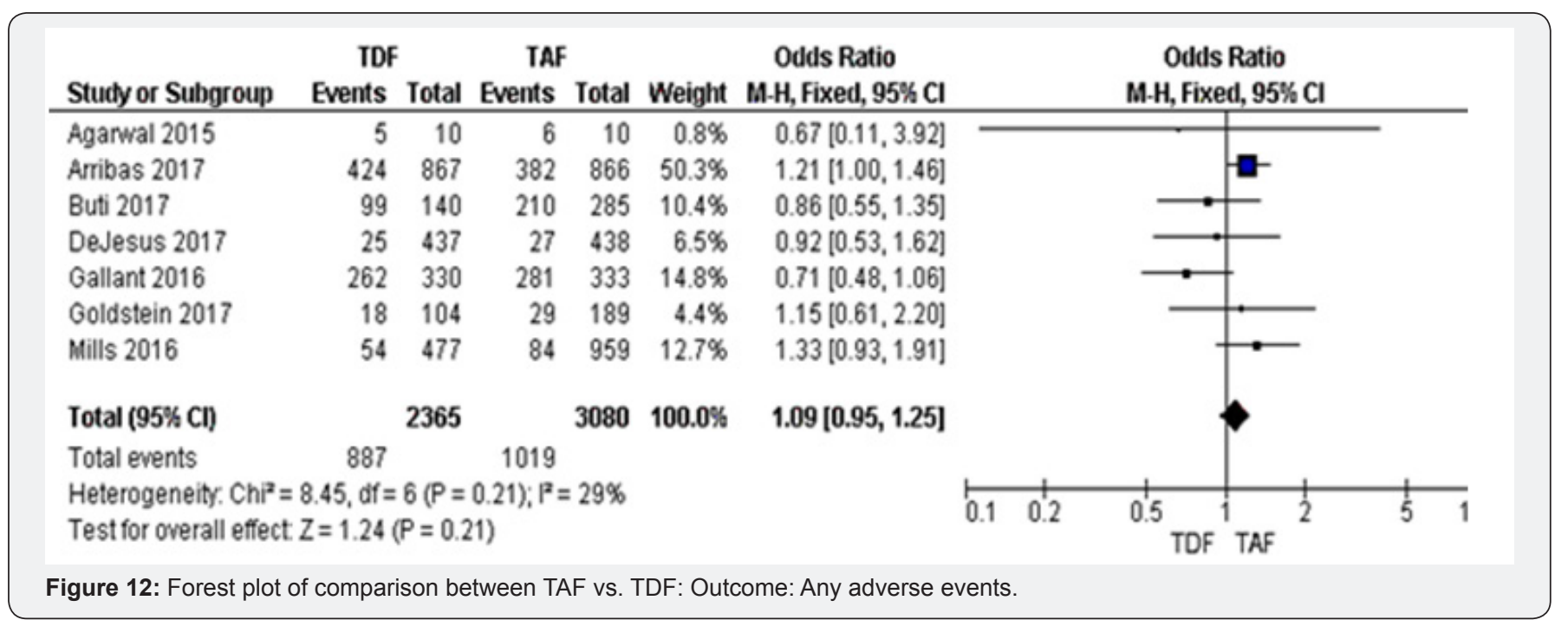

Any adverse events (96 weeks): The effect of TAF compared to TDF on any adverse events was not statistically significant with OR 1.09 (95\% CI 0.95 to $1.25,7$ studies, $\mathrm{P}=0.21$ ), with high evidence graded (Figure 12).
Serious adverse events ( 48 to 144 week): Serious adverse events were balanced in both TAF and TDF groups. The results with high evidence (Figure 13). 


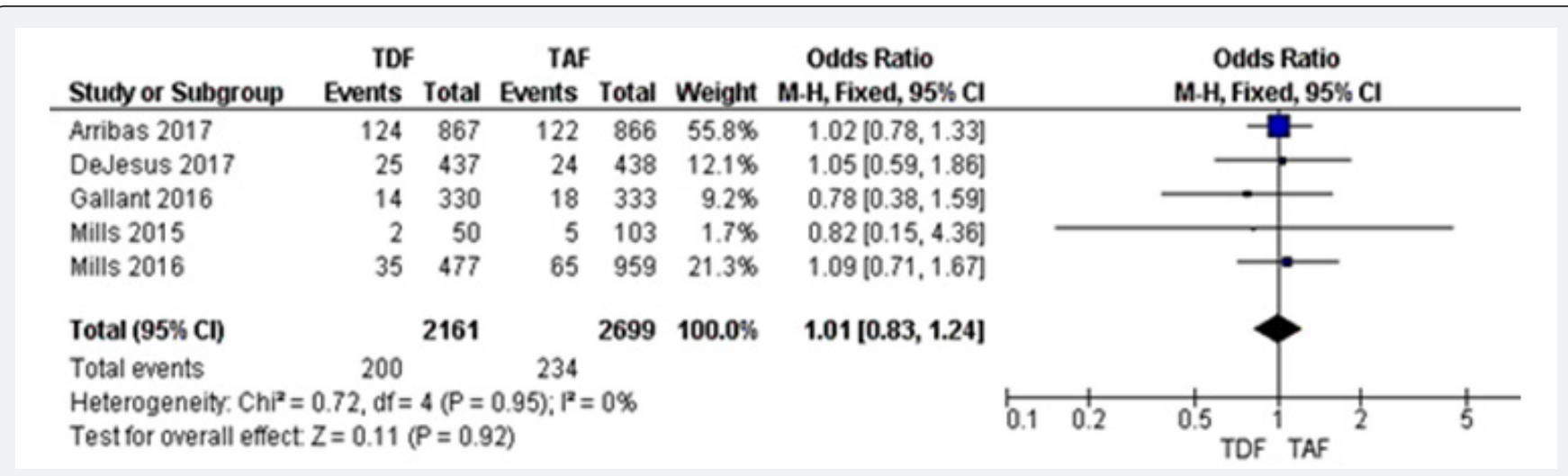

Figure 13: Forest plot of comparison between TAF vs. TDF: Outcome: Serious adverse events.

\section{Subgroups analysis}

Subgroup analyses were undertaken based on different baseline viral load and ART regimens. The aim was to estimate a treatment effect of different ART regimens. Two meta-analyses obtained more $75 \%$ of heterogeneity basically Creatinine
Clearance rate $(\mathrm{ml} / \mathrm{min})$ and Mean percentage change Hip Bone Mineral Density (\%). We differentiated studies with baseline viral load less than 50RNA/ml and those with viral above 1000RNA/ ml. Among studies, three ART regimens were accounted:

Glomerular filtration rate $(\mathrm{ml} / \mathrm{min})$ (Figure $14 \& 15)$

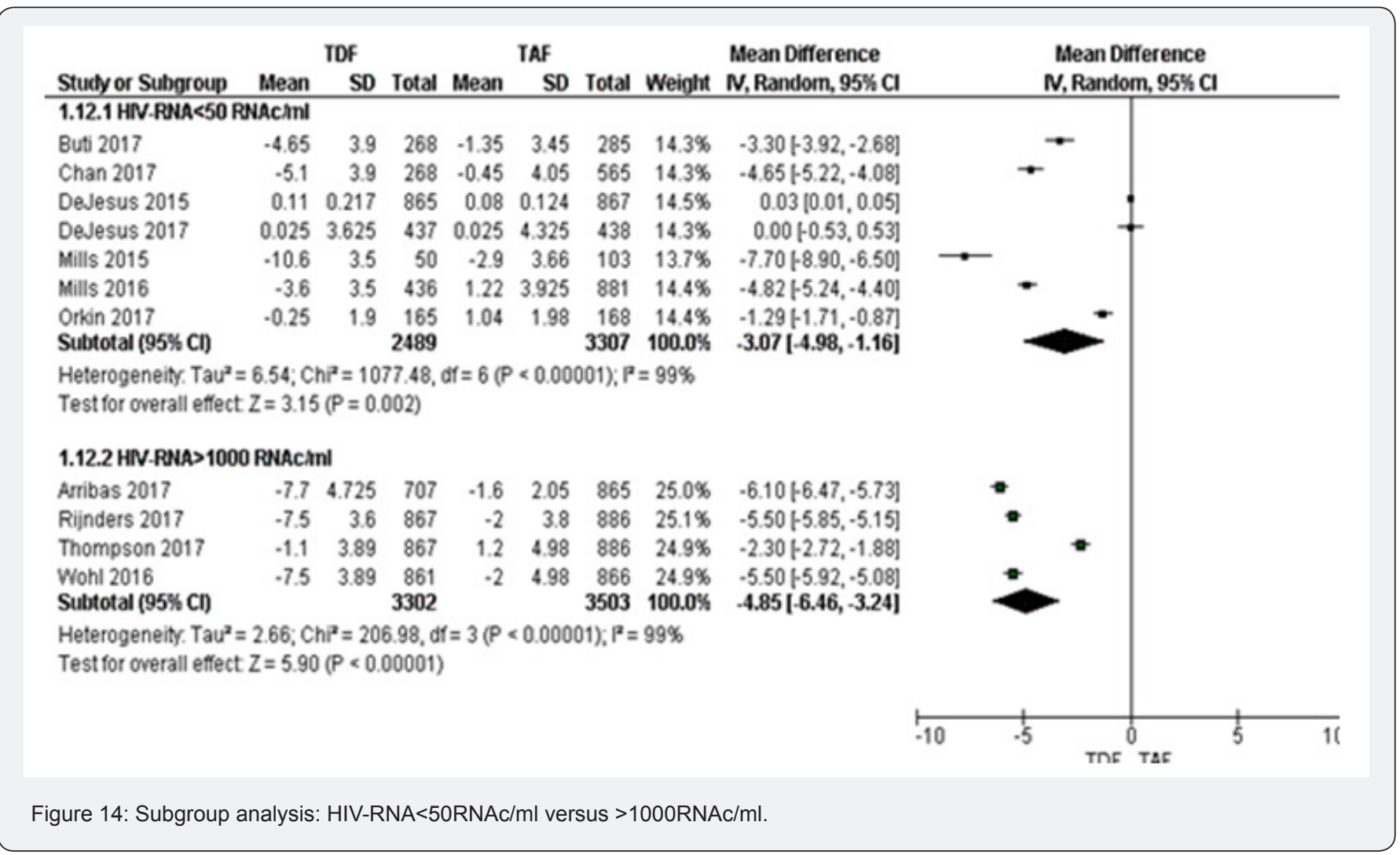




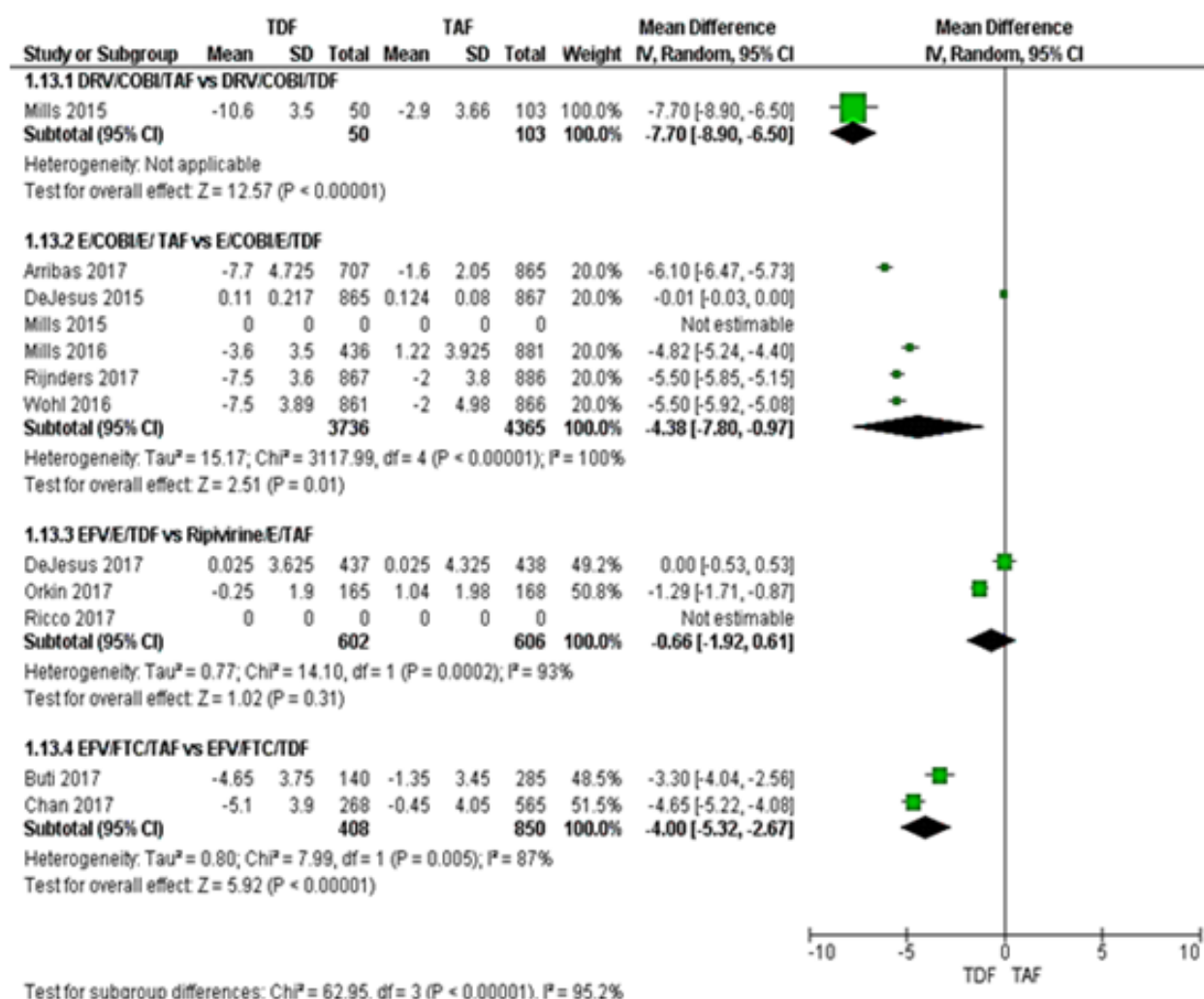

Figure 15: Subgroup analysis: ART regimens.

Subgroup of HIV-RNA: The test for subgroup difference did not show any between HIV-RNA $<50 \mathrm{RNAc} / \mathrm{ml}$ to $>1000 \mathrm{RNAc} / \mathrm{ml}$.

Subgroup of different ART regimens: Subgroup analysis between different ART regimens has illustrated that kidney injury could be more frequent in Ripivirine/E/TDF compared to DRV/COBI/ TDF, E/COBI/E/ TDF and EFV/FTC/TDF. DRV/COBI/TDF and
EFV/FTC/TDF subgroups have shown highly significant results. Mean percentage change Hip BMD (\%)

Subgroup of HIV-RNA: The test for subgroup analysis between $\mathrm{HIV}-\mathrm{RNA}<50 \mathrm{RNAc} / \mathrm{ml}$ to $>1000 \mathrm{RNAc} / \mathrm{ml}$ was not statistically significant $(\mathrm{P}=0.10)$ (Figure 16).

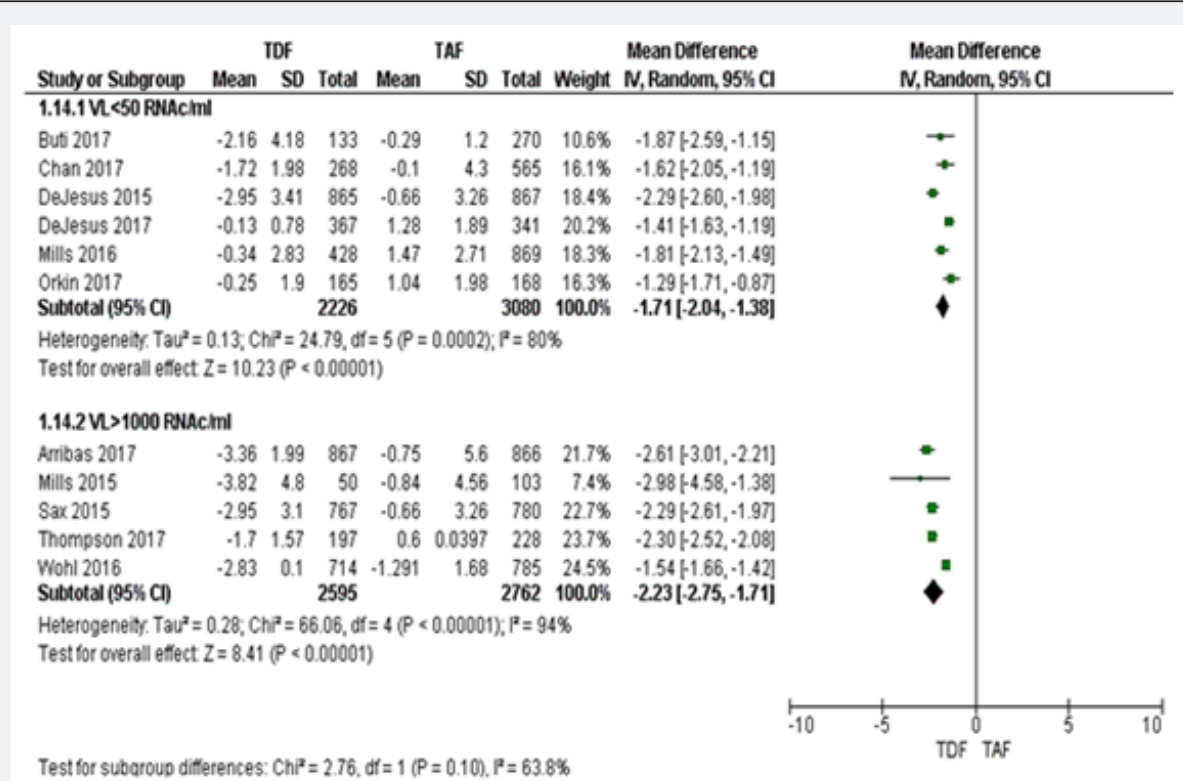

Figure 16: Subgroup analysis: HIV-RNA<50RNAc/ml to versus $1000 R N A c / m l$. 
Subgroup of different ART regimens: Subgroup analysis between $\quad \mathrm{P}=0.41$ (Figure 17). different ART regimens was not statistically significant with

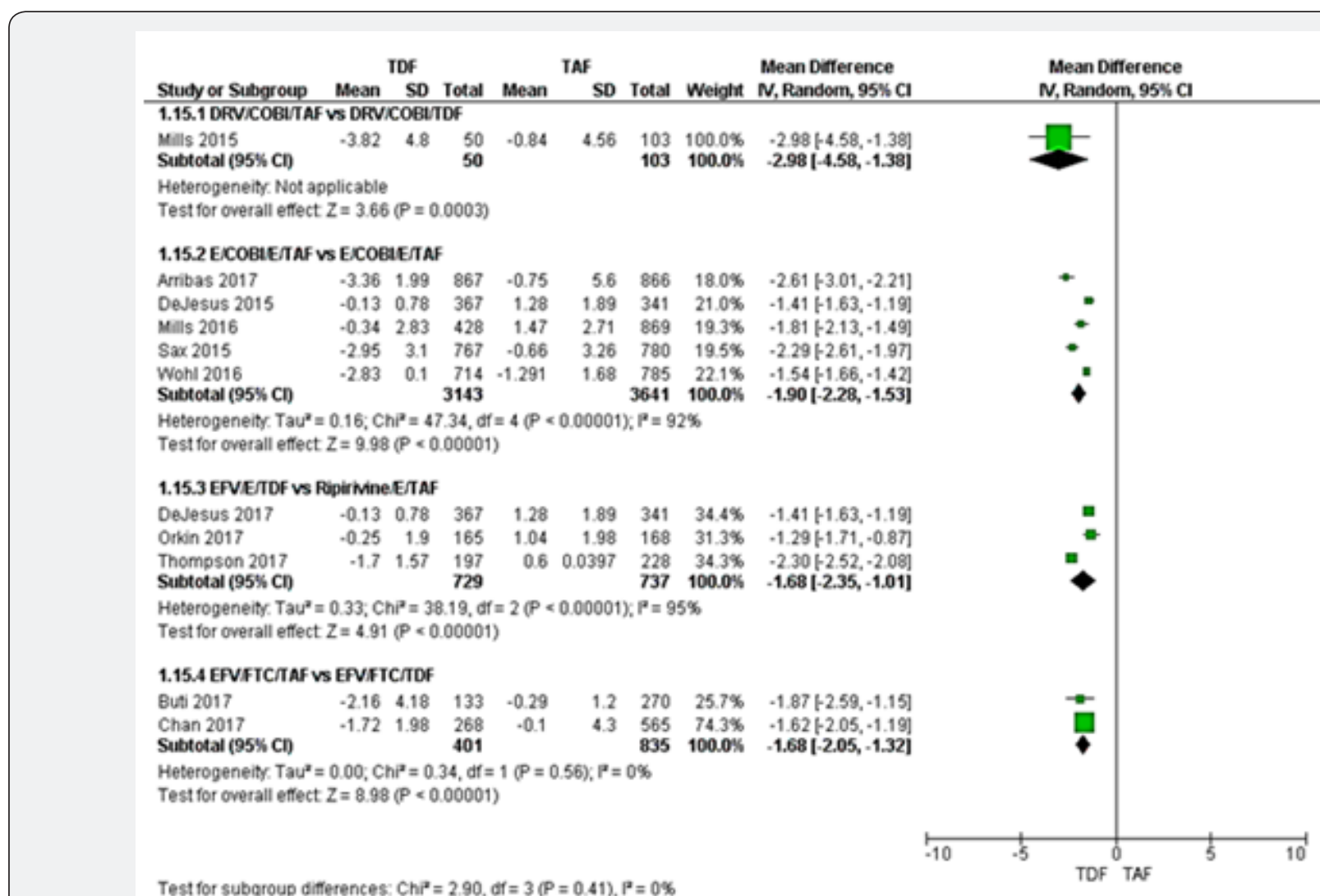

Figure 17: Subgroup analysis: ART regimens.

\section{Discussion}

This systematic review has implications for patient care, guidelines, and HIV programmes. For clinicians, TAF constitutes the main stone of future ART regimens. These findings can inform evidence-based guideline development and influence the WHO ART guidelines advocating universal treatment of TAF in HIV. Our review has limitations. We used amputation to deal with missing data. Data extraction was amputated in three outcomes: Glomerular filtration rate $(\mathrm{ml} / \mathrm{min})$, Mean percentage change Hip Bone Mineral Density (\%) and Mean percentage change Spine Bone Mineral Density (\%). All studies were conducted in America, Europe, Asia and Australia. We did not find any study conducted in Sub-Saharan Africa where HIV prevalence is the highest in the world and clinical practice has shown a significant increase of CKDs. TAF based regimens could improve CKDs in Sub-Saharan Africa where CKDs are rising up. Although we did not find a study in Sub-Saharan Africa, the meta-analysis was robust enough. Then, the evidence could still imply large implication of the study.

Concerning the HIV-RNA<50RNAc/ml from 48 to 96 weeks, there was a high evidence that TDF group was $13 \%$ less likely to achieve $\mathrm{VL}<50 \mathrm{RNAc} / \mathrm{ml}$ compared to TAF group. This result was statistically significant with p-value of 0.02 . This could imply good clinical practice of TAF in lowering HIV-RNA. Moreover, TDF individuals had a low MD of CD4 count (cells/ $\mu \mathrm{l}$ ) than TAF group (MD -18.99, 6 studies, $\mathrm{P}<00001$ ) with high level of evidence. This means immunological and virological parameters were well controlled with TAF. In both TAF and TDF, there was high evidence that virological Failure and proteinuria were balanced. Even so, the likelihood of proteinuria was high in TDF group even if the results were not statistically significant. The MDs of percentage change BMD was decreased in TFD compared to TAF. This could predispose TDF group to bone injuries [34]. But the evidence was low and moderate for low hip and spine BMD respectively. The HBV- DNA between TAF and TDF was increased to $29 \%$ with $\mathrm{P}=0.02$, showing that TAF is more beneficial than TDF in the management of HIV/Hepatitis B coinfection. Additionally, ALT above ULN was reduced by $25 \%$ in TAF group compared to TDF group $(\mathrm{P}=0.04)$. Lastly, the sides effects were estimated the same in both TAF and TDF groups.

Statistical heterogeneity was high for summary statistics from both Glomerular filtration rate $(\mathrm{ml} / \mathrm{min})$ and Mean percentage change Hip Bone Mineral Density (\%). We conducted subgroup analysis to clarify the reasons of variability. Subgroup analysis has revealed the test for subgroup difference did 
not shown any difference between studies with baseline $\mathrm{VL}<50 \mathrm{RNAc} / \mathrm{ml}$ and $>1000 \mathrm{RNAc} / \mathrm{ml}$. Subgroup analysis between different ART regimens has illustrated that kidney injury could be more frequent in Ripivirine/E/TDF compared to DRV/COBI/ TDF, E/COBI/E/ TDF and EFV/FTC/TAF. DRV/COBI/TDF and EFV/FTC/TDF subgroups have shown highly significant results. This subgroup analysis could influence broadly clinical practice. In fact, DRV/COBI/TDF and EFV/FTC/TDF may be used in high risk patients with nephrotoxic co-morbidities among which high basal serum creatinine (Cr) level, low body weight, old age, hypertension, diabetes mellitus and low CD4+ T cell count.

Essentially, internal consistency between results from different analyses increases the confidence in our conclusions. In truth, all meta-analysis included RCTs with very low risk of bias. Random sequence generation was adequate in all RCTs (100\% of studies). Allocation concealment was well control in $39 \%$ of RCTs. $61 \%$ of them included unclear allocation concealment. Blinding of participants and personnel was minimized by $67 \%$ in all included studies, $27 \%$ of RCTs revealed high risk of performance bias and $8 \%$ was unclear. Blinding of outcome was well control in all included studies $(100 \%$ low risk of bias). Incomplete outcome data was less common, only $11 \%$ of RCTs were high risk of bias. $22 \%$ of studies included high risk of publication bias. However, we assessed publication bias using the funnel plots. All the funnel plot of comparison among which HIV-RNA<50RNAc/m, glomerular filtration rate, hip and spine BMD (\%) were asymmetrical in visual assessment. We assessed asymmetrical funnel plot using Egger's test. Therefore, the Egger test demonstrated that HIV-RNA $<50$ RNA/m was symmetrical (Egger's test $=0.57, \mathrm{P}=0.865$ ). Other funnel plots were asymmetric with Egger's test p-values less than 0.5. This is the main weakness of this review. Besides, $17 \%$ of RCTs included other type of bias.

It is important to place TAF based regimen in the context of public health interventions in high HIV epidemic regions and where CKDs prevalence are rising up. Our results suggest TAF contained will reduce the pool of highly susceptible CKDs. Evidence for the benefit of TAF over TDF in reducing HIV-RNA and HBV DNA, increasing CD4 cells, preventing CKDs and loss of bone mineral density should be recommended in HIV or/ and Hepatitis B therapy and preventing TDF related toxicity. The sides' effects were balanced in both TAF and TDF groups. Improving all those outcomes may also be beneficial in patients with co-morbidities. Then, TAF could be used in hypertension, diabetes mellitus and HIV co-morbidities [19-20]. Thus, scale-up of HIV therapy could lead to fewer patients developing CKDs and HIV related co-morbidities. By the way this is likely to be one of the most effective public health strategies to reduce TDF drug toxicity; similarly, best way of enhancing HIV/Hepatitis B coinfection, reducing the risk of hepatitis B complications [56-70].

\section{Conclusion}

Evidence suggests that use of TAF is more protective and effective than either TDF. Improving renal and hepatic related co-morbidities in HIV-infected population, TAF may be beneficial in public health policy, specifically in high HIV epidemic regions. Based on the results, TAF has illustrated its efficacy in all outcomes included in this review. Findings from this study may be helpful in preventing CKD in low and middle income countries. In reality, several barriers are impacting in close kidneys monitoring in low income countries. In addition, we recommend TAF based regimens in case of HIV associated to high CKD population (Hypertension, diabetes mellitus, old age...). Lastly, TAF contained regimens are more effective than TDF based regimens in the management of HIV/Hepatitis B coinfection. This review has a broad application in clinical practice. However, economic evaluation studies should be undertaken in resource limited countries.

\section{Acknowledgment}

We sincerely thank Dr JL. Tshimwanga for reviewing this article. Dr ANH Bulabula edited and reviewed the article. Dr LM Muyaya and Dr JL Tamuzi critically appraised included, ongoing and excluded studies. JL Tamuzi conceived and registered the review on International prospective register of systematic reviews (Pospero); he conducted electronic search, critically appraised studies, extracted data, conducted meta-analysis, assessed the risk of bias and wrote the review.

\section{Conflict of Interest}

The authors have not declared any conflict of interests.

\section{References}

1. UNAIDS (2017) Fact sheet - Latest statistics on the status of the AIDS epidemic.

2. (2016) Global HIV and Aids Statistics.

3. World Health Organization (2017) Medical Centre, Fact sheetsHepatitis B. Geneva, Switzerland.

4. Losina E, Schackman BR, Sadownik SN, Gebo KA, Walensky RP, et al. (2009) Racial and sex disparities in life expectancy losses among HIVinfected persons in the United States: impact of risk behavior, late initiation, and early discontinuation of antiretroviral therapy. Clin Infect Dis 49(10): 1570-1578.

5. Nakagawa F, Lodwick RK, Smith CJ, Smith R, Cambiano V, et al. (2012) Projected life expectancy of people with HIV according to timing of diagnosis. AIDS 26(3): 335-343.

6. Neto LF, Bassetti BR, Fraga IH, Santos CR, Ximenes PD, et al. (2016) Nephrotoxicity during tenofovir treatment: a three-year follow-up study in a Brazilian reference clinic. The Brazilian journal of infectious diseases: an official publication of the Brazilian Society of Infectious Diseases 20(1): 14-18.

7. Gupta SK (2005) Tenofovir and changes in renal function. Clinical infectious diseases 41(4): 570-571. 
8. Sax PE, Gallant JE, Klotman PE (2007) Renal safety of tenofovir disoproxil fumarate. AIDS Read 17(2): 90-2, 99-104, C3.

9. Cooper RD, Wiebe N, Smith N, Keiser P, Naicker S, etal. (2010) Systematic review and meta-analysis: renal safety of tenofovir disoproxil fumarate in HIV-infected patients. Clin Infect Dis 51(5): 496-505.

10. Jin S, Kim MH, Park JH, Jung HJ, Lee HJ, et al. (2015) The Incidence and Clinical Characteristics of Acute Serum Creatinine Elevation more than $1.5 \mathrm{mg} / \mathrm{dL}$ among the Patients Treated with Tenofovir/Emtricitabinecontaining HAART Regimens. Infect Chemother 47(4): 239-246.

11. Sax PE (2003) Meeting notes from the 43rd Interscience Conference on Antimicrobial Agents and Chemotherapy (ICAAC). New NNRTI resistance mutations. AIDS clinical care 15(11): 96.

12. Wood SM, Shah SS, Steenhoff AP, Meyers KE, Kaplan BS, et al. (2009) Tenofovir-associated nephrotoxicity in two HIV-infected adolescent males. AIDS patient care and STDs 23(1): 1-4.

13. Goicoechea M, Liu S, Best B, Sun S, Jain S, et al. (2008) Greater tenofovirassociated renal function decline with protease inhibitor-based versus nonnucleoside reverse-transcriptase inhibitor-based therapy. J Infect Dis 197(1):102-108.

14. Young J, Schafer J, Fux CA, Furrer H, Bernasconi E, et al. (2012) Renal function in patients with HIV starting therapy with tenofovir and either efavirenz, lopinavir or atazanavir. AIDS 26(5): 567-575.

15. Antonello VS, Antonello IC, Herrmann S, Tovo CV (2015) Proteinuria is common among HIV patients: what are we missing? Clinics (Sao Paulo) 70(10): 691-695.

16. Szczech LA, Gange SJ, van der Horst C, Bartlett JA, Young M, et al. (2002) Predictors of proteinuria and renal failure among women with HIV infection. Kidney international 61(1): 195-202.

17. Banerjee T, Scherzer R, Powe NR, Steffick D, Shahinian V, et al. (2014) Race and other risk factors for incident proteinuria in a national cohort of HIV-infected veterans. J Acquir Immune Defic Syndr 67(2): 145-152.

18. Roling J, Schmid H, Fischereder M, Draenert R, Goebel FD (2006) HIVassociated renal diseases and highly active antiretroviral therapyinduced nephropathy. Clin Infect Dis 42(10): 1488-1495.

19. Markowitz M, Zolopa A, Squires K, Ruane P, Coakley D, et al. (2014) Phase I/II study of the pharmacokinetics, safety and antiretroviral activity of tenofovir alafenamide, a new prodrug of the HIV reverse transcriptase inhibitor tenofovir, in HIV-infected adults. J Antimicrob Chemother 69(5): 1362-1369.

20. Birkus G, Wang R, Liu X, Kutty N, MacArthur H, et al. (2007) Cathepsin $A$ is the major hydrolase catalyzing the intracellular hydrolysis of the antiretroviral nucleotide phosphonoamidate prodrugs GS-7340 and GS-9131. Antimicrob Agents Chemother 51(2): 543-550.

21. Margot NA, Kitrinos KM, Fordyce M, McCallister S, Miller MD, et al. (2016) Rare emergence of drug resistance in HIV-1 treatment-naïve patients after 48 weeks of treatment with elvitegravir/cobicistat/ emtricitabine/tenofovir alafenamide. HIV Clin Trials 17(2): 78-87.

22. Lee WA, He GX, Eisenberg E, Cihlar T, Swaminathan S, et al. (2005) Selective intracellular activation of a novel prodrug of the human immunodeficiency virus reverse transcriptase inhibitor tenofovir leads to preferential distribution and accumulation in lymphatic tissue. Antimicrob Agents Chemother 49(5): 1898-1906.

23. Eisenberg EJ, He GX, Lee WA (2001) Metabolism of GS-7340, a novel phenyl monophosphoramidate intracellular prodrug of PMPA, in blood. Nucleosides Nucleotides Nucleic Acids 20(4-7): 1091-1098.

24. Bam RA, Birkus G, Babusis D, Cihlar T, Yant SR (2014) Metabolism and antiretroviral activity of tenofovir alafenamide in CD4+ T-cells and macrophages from demographically diverse donors. Antivir Ther 19(7): 669-677.
25. Ruane PJ, DeJesus E, Berger D, Markowitz M, Bredeek UF, et al. (2013) Antiviral activity, safety, and pharmacokinetics/pharmacodynamics of tenofovir alafenamide as 10-day monotherapy in HIV-1-positive adults. J Acquir Immune Defic Syndr 63(4): 449-455.

26. Sax PE, Wohl D, Yin MT, Post F, DeJesus E, et al. (2015) Tenofovir alafenamide versus tenofovir disoproxil fumarate, co-formulated with elvitegravir, cobicistat, and emtricitabine, for initial treatment of HIV1 infection: two randomised, double-blind, phase 3, non-inferiority trials. Lancet 385(9987): 2606-2615.

27. Babusis D, Phan TK, Lee WA, Watkins WJ, Ray AS (2013) Mechanism for effective lymphoid cell and tissue loading following oral administration of nucleotide prodrug GS-7340. Mol Pharm 10 (2): 459-466.

28. Antela A, Aguiar C, Compston J, Hendry BM, Boffito M, et al. (2016) The role of tenofovir alafenamide in future HIV management. HIV Med 17 Suppl 2: 4-16.

29. Bonora S, Calcagno A, Trentalange A, Di Perri G (2016) Elvitegravir, cobicistat, emtricitabine and tenofovir alafenamide for the treatment of HIV in adults. Expert Opin Pharmacother 17(3): 409-419.

30. De Clercq E (2016) Tenofovir alafenamide (TAF) as the successor of tenofovir disoproxil fumarate (TDF). Biochem Pharmacol 119: 1-7.

31. Wohl D, Oka S, Clumeck N, Clarke A, Brinson C, et al. (2016) Brief Report: A Randomized, Double-Blind Comparison of Tenofovir Alafenamide Versus Tenofovir Disoproxil Fumarate, Each Coformulated With Elvitegravir, Cobicistat, and Emtricitabine for Initial HIV-1 Treatment: Week 96 Results. J Acquir Immune Defic Syndr 72(1): 58-64.

32. Dhanireddy S, Baeten JM (2016) Tenofovir alafenamide for HIV: time to switch? The Lancet. Infectious diseases 16(1): 3-5.

33. Gibson AK, Shah BM, Nambiar PH, Schafer JJ (2016) Tenofovir Alafenamide: A Review of Its Use in the Treatment of HIV-1 Infection. Ann Pharmacother 50(11): 942-952.

34.Greig SL, Deeks ED (2016) Elvitegravir/Cobicistat/Emtricitabine/ Tenofovir Alafenamide: A Review in HIV-1 Infection. Drugs 76(9):957968.

35. Leleu H, Rodriguez I, Blachier M, Pentel J (2015) Indirect Comparison for E/C/F/Taf in Treatment Naive Hiv Patients. Value Health 18(7): A578.

36. Ogawa E, Furusyo N, Nguyen MH (2017) Tenofovir alafenamide in the treatment of chronic hepatitis B: design, development, and place in therapy. Drug design, development and therapy 11: 3197-3204.

37. Pozniak A, Arribas JR, Gathe J, Gupta SK, Post FA, et al. (2016) Switching to Tenofovir Alafenamide, Coformulated With Elvitegravir, Cobicistat, and Emtricitabine, in HIV-Infected Patients With Renal Impairment: 48-Week Results From a Single-Arm, Multicenter, Open-Label Phase 3 Study. J Acquir Immune Defic Syndr 71(5): 530-537.

38. Gilead Sciences (2017) Tenofovir Alafenamide Versus Tenofovir Disoproxil Fumarate for Treatment of Hepatitis B e Antigen-Negative Hepatitis B.

39. Quinn KJ, Emerson CR, Dinsmore WW, Donnelly CM (2010) Incidence of proximal renal tubular dysfunction in patients on tenofovir disoproxil fumarate. Int J STD AIDS AIDS 21(2): 150-151.

40. Cochrane Collaboration (2003) Review Manager (RevMan) Version 4.2 for Windows. Copenhagen (DK): The Nordic Cochrane Centre.

41. Higgins JP, Green S (Eds.) (2011) Cochrane handbook for systematic reviews of interventions John Wiley \& Sons 4.

42. Wyatt CM (2016) Will a new tenofovir prodrug for the treatment of HIV reduces the risk of nephrotoxicity? Kidney Int 89(1): 5-6.

43. Ray AS, Fordyce MW, Hitchcock MJ (2016) Tenofovir alafenamide: A novel prodrug of tenofovir for the treatment of Human Immunodeficiency Virus. Antiviral Res 125: 63-70. 
44. Aloy B, Tazi I, Bagnis CI, Gauthier M, Janus N, et al. (2016) Is tenofovir alafenamide safer than tenofovir disoproxil fumarate for the kidneys? AIDS Rev 18(4): 184-192.

45. Custodio JM, West S, Patel H, Ling KHJ, Cao H, et al. (2016) The relative bioavailability of rilpivirine following administration of the new tenofovir alafenamide singletablet regimen rilpivirine/emtricitabine/ tenofovir alafenamide vs rilpivirine/emtricitabine/tenofovir disoproxil fumarate. Clinical Pharmacology in Drug Development. Conference: 2016 Annual Meeting of the American College of Clinica Pharmacology. USA, Conference Start: 20160925. Conference End: 20160927 5: 9-10.

46. Garcia M, Le Moal G, Godet C, Beraud G, Chagneau Derrode C, et al. (2016) First case report of renal improvement on tenofovir alafenamide in an HIV/hepatitis B virus-co-infected patient with adefovir-induced Fanconi's syndrome. AIDS 30(9): 1487-1488.

47. Gaur AH, Kizito H, Prasitsueubsai W, Rakhmanina N, Rassool M, et al. (2017) Safety, efficacy, and pharmacokinetics of a single-tablet regimen containing elvitegravir, cobicistat, emtricitabine, and tenofovir alafenamide in treatment-naive, HIV-infected adolescents: a single-arm, open-label trial. The lancet HIV 3(12): e561-e568.

48. Hsu YC, Wei MT, Nguyen MH (2017) Tenofovir alafenamide as compared to tenofovir disoproxil fumarate in the management of chronic hepatitis B with recent trends in patient demographics. Expert Rev Gastroenterol Hepatol 11(11): 999-1008.

49. Suk LY, Tatsuya I, Simone S (2016) Minimal Changes in Urine Markers of Tubular Dysfunction in CHB Patients Receiving Tenofovir alafenamide (TAF) compared with Tenofovir Disoproxil Fumarate (TDF). Hepatology 64: 940A-940A.

50. Marcellin P, Buti M, Krastev Z, de Man RA, Zeuzem S, et al. (2014) Kinetics of hepatitis B surface antigen loss in patients with $\mathrm{HBeAg}$ positive chronic hepatitis B treated with tenofovir disoproxil fumarate. J Hepatol 61(6): 1228-1237.

51. Murakami E, Wang T, Park Y, Hao J, Lepist EI, et al. (2015) Implications of efficient hepatic delivery by tenofovir alafenamide (GS-7340) for hepatitis B virus therapy. Antimicrob Agents Chemother 59(6): 3563 3569.

52. Post FA, Tebas P, Clarke A, Cotte L, Short W, et al. (2016) Switching to Tenofovir Alafenamide, Coformulated With Elvitegravir, Cobicistat, and Emtricitabine, in HIV-Infected Adults With Renal Impairment: 96-Week Results From a Single-Arm, Multicenter, Open-Label Phase 3 Study. J Acquir Immune Defic Syndr 71(5): 530-537.

53. Raffi F, Orkin C, Clarke A, Slama L, Gallant J, et al. (2017) Brief Report: Long-Term (96-Week) Efficacy and Safety After Switching From Tenofovir Disoproxil Fumarate to Tenofovir Alafenamide in HIVInfected, Virologically Suppressed Adults. J Acquir Immune Defic Syndr 75(2): 226-231

54. Agarwal K, Fung SK, Nguyen TT, Cheng W, Sicard E, et al. (2015) Twenty-eight day safety, antiviral activity, and pharmacokinetics of tenofovir alafenamide for treatment of chronic hepatitis B infection. J Hepatol 62(3): 533-540.

55. Arribas JR, Thompson M, Sax PE, Haas B, McDonald C, et al. (2017) Brief Report: Randomized, Double-Blind Comparison of Tenofovir Alafenamide (TAF) vs Tenofovir Disoproxil Fumarate (TDF), Each Coformulated With Elvitegravir, Cobicistat, and Emtricitabine (E/C/F) for Initial HIV-1 Treatment: Week 144 Results. J Acquir Immune Defic Syndr 75(2): 211-218.

56. Brunetto MR, Lim YL, Gane E, Seto WK, Osipenko M, et al. (2017) Week 96 Efficacy and Safety Results of Tenofovir Alafenamide (TAF) Comparing to Tenofovir Disoproxil Fumarate (TDF) in Chronic Hepatitis B (CHB), HBEAG-Negative, Chronic Hepatitis B Patients: A Global Phase 3 Study. Gastroenterogy 152: S1086.
57. Buti M, Gane E, Seto WK, Chan HLY, Chuang WL, et al. (2017) Tenofovir alafenamide versus tenofovir disoproxil fumarate for the treatment of patients with HBeAg-negative chronic hepatitis B virus infection: a randomized, double-blind, phase 3, non-inferiority trial. Lancet Gastroenterol Hepatol 1(3): 196-206.

58. Chan HLY, Fung S, Seto WK, Chuang WL, Chen CY, et al. (2017) Tenofovir alafenamide versus tenofovir disoproxil fumarate for the treatment of HBeAg-positive chronic hepatitis B virus infection: a randomized, double-blind, phase 3, non-inferiority trial. Lancet Gastroenterol Hepatol 1(3): 185-195

59. DeJesus E, Sax P, Yin M, Post F, Oka S, et al. (2015) Renal and bone safety of tenofovir alafenamide versus tenofovir disoproxil fumarate. Journal of the International AIDS Society 18:24.

60. Ramgopal, DG Crofoot, P Ruane, A LaMarca, CT Mills, et al. (2017) Switching from efavirenz, emtricitabine, and tenofovir disoproxil fumarate to tenofovir alafenamide coformulated with rilpivirine and emtricitabine in virally suppressed adults with HIV-1 infection: a randomized, double-blind, multicentre, phase $3 \mathrm{~b}$, non-inferiority study. The lancet HIV (5): e205-e213.

61. Gallant J, Brunetta J, Crofoot G, Benson P, Mills A, et al. (2016) Efficacy and Safety of Switching to a Single-Tablet Regimen of Elvitegravir/ Cobicistat/Emtricitabine/Tenofovir Alafenamide (E/C/F/TAF) in HIV1/Hepatitis B Coinfected Adults. J Acquir Immune Defic Syndr 73(3): 294-298.

62. Gane EJ, Saito M, Bae SH, Andreone P, Flaherty JF, et al. (2017) Characterization of host, viral, and treatment-related factors associated with antiviral efficacy of tenofovir alafenamide (TAF) and tenofovir disporoxil (TDF). Hepatology. Conference: 67 th annual meeting of the American association for the study of liver diseases: the liver meeting 2016. USA. Conference start: 20161111. Conference end: 20161115 63(1 Supplement 1): 929A-930A.

63. Goldstein D, Ward D, Brinson C, Crofoot G, Ryu J, et al. (2017) Week 96 efficacy and safety of tenofovir alafenamide (TAF) versus tenofovir disoproxil fumarate (TDF) in older, HIV infected virologicallysuppressed adults. Journal of the American geriatrics society. Conference: 2017 annual scientific meeting of the american geriatrics society. United States 65: S48.

64. Mills A, Crofoot G, McDonald C, Shalit P, Flamm JA, et al. (2015) Tenofovir Alafenamide Versus Tenofovir Disoproxil Fumarate in the First Protease Inhibitor-Based Single-Tablet Regimen for Initial HIV-1 Therapy: A Randomized Phase 2 Study. J Acquir Immune Defic Syndr 69(4): 439-45.

65. Mills A, Arribas JR, Villanueva AJ, DiPerri G, Van Lunzen J, et al. (2016) Switching from tenofovir disoproxil fumarate to tenofovir alafenamide in antiretroviral regimens for virologically suppressed adults with HIV-1 infection: A randomized, active-controlled, multicentre, openlabel, phase 3, non-inferiority study. Lancet Infect Dis 16(1): 43-52.

66. Orkin C, DeJesus E, Ramgopal M, Crofoot G, Ruane P, et al. (2017) Switching from tenofovir disoproxil fumarate to tenofovir alafenamide coformulated with rilpivirine and emtricitabine in virally suppressed adults with HIV-1 infection: a randomized, double-blind, multicentre, phase 3b, non-inferiority study. Lancet HIV 4(5): e195-e204.

67. G Ricco, M Buti, M Omata, YJ Kim, Coco B, et al. (2017) Comparative antiviral efficacy with higher ALT normalization of tenofovir alafenamide (TAF) versus tenofovir disoproxil fumarate (TDF) in HBeAg-negative, genotype D chronic hepatitis B. Digestive and Liver Disease 49S: e43-e70.

68. Rijnders BJ, Post FA, Rieger A, Teofilo E, Wohl D, et al. (2017) Longerterm renal safety of tenofovir alafenamide vs tenofovir disoproxil fumarate. Topics in antiviral medicine. Conference: 23rd conference on retroviruses and opportunistic infections, CROI 2016. United States. Conference start: 20160222. Conference end: 20160225 24(E-1): 283. 
69. Thompson A, Gane E, Fung S, Seto WK, Flaherty JF, et al. (2017) Improved bone and renal safety of switching from tenofovir disoproxil fumarate to tenofovir alafenamide: preliminary results from two phase 3 studies in HBeAg-positive and HBeAg-negative patients with chronic hepatitis B. Journal of gastroenterology and hepatology (Australia) Conference: 2017 gastroenterological society of Australia, Australian gastroenterology week. Australia 32: 109.
70. Thompson A, Gane E, Fung S, Seto WK, Flaherty JF, et al. (2017) Improved bone and renal safety of switching from tenofovir disoproxil fumarate to tenofovir alafenamide: preliminary results from two phase 3 studies in HBeAg-positive and HBeAg-negative patients with chronic hepatitis B. Journal of gastroenterology and hepatology (Australia). Conference: 2017 gastroenterological society of Australia, Australian gastroenterology week. 32: 109.

\section{Your next submission with Juniper Publishers} will reach you the below assets

- Quality Editorial service

- Swift Peer Review

- Reprints availability

- E-prints Service

- Manuscript Podcast for convenient understanding

- Global attainment for your research

- Manuscript accessibility in different formats ( Pdf, E-pub, Full Text, Audio)

- Unceasing customer service

Track the below URL for one-step submission https://juniperpublishers.com/online-submission.php 